\title{
The effect of free surface on cloud cavitating flow around a blunt body *
}

\author{
Chang Xu (徐畅) ${ }^{1,2}$, Yi-wei Wang (王一伟 $)^{1,2}$, Chen-guang Huang (黄晨光 $)^{1,2}$, Jian Huang (黄荐) ${ }^{1,2}$, \\ Chao Yu (余超) ${ }^{1,2}$, \\ 1. Key Laboratory for Mechanics in Fluid Solid Coupling Systems, Institute of Mechanics, Chinese Academy of \\ Sciences, Beijing 100190, China \\ 2. School of Engineering Science, University of Chinese Academy of Sciences, Beijing 100049, China, \\ E-mail: xuchang@imech.ac.cn
}

(Received August 24, 2017, Revised September 6, 2017)

\begin{abstract}
In this study, the effect of the free surface on the cloud cavitating flow around a blunt body is investigated based on the water tank experiment and the CFD method. Numerical results are in good agreement with experimental data, and the mesh independence of the methods is verified. The cavity evolution process includes the cavity growth, the re-entrant jet, the cavity shedding, and the collapse, which can all be observed from the water tank experiment. The effects of the free surface on the cavity length, the thickness, and the cavity evolution period are analyzed by comparing the difference between the cavitating flows on the upper and lower sides of the body. This study also examines the effect of the distance between the free surface and the model through a series of water tank experiments and numerical simulations. The cavity stability and asymmetry, as well as the thickness and the velocity of the re-entrant jet inside the cavity, which varies with the submerged depth, are discussed with consideration of the effect of the free surface. The effect of the free surface on the cavitating flow around the blunt body is enhanced with the decrease of the submerged depth.
\end{abstract}

Key words: Cavitation, multiphase flow, water tank experiment, CFD, free surface

\section{Introduction}

The cavitation is one of the classic problems in high-speed hydrodynamics when underwater vehicles move in great speed ${ }^{[1-4]}$. The induced instable phenomena can cause serious consequences, such as noises, erosion, and vibrations of the structure. The problem becomes complicated when the interaction between the free surface and the cloud cavitating flow on the model is considered. The water tunnel ${ }^{[5]}$ and water $\operatorname{tank}^{[6,7]}$ tests are usually performed to analyze the problem. In recent years, the CFD method becomes one of the main research methods used for the cavitation flow, including the potential flow theory ${ }^{[8,9]}$, the boundary element method (BEM) ${ }^{[10-12]}$, the large eddy simulation (LES) ${ }^{[13-16]}$, and other approaches ${ }^{[17-19]}$

* Project supported by the National Natural Science Foundation of China (Grant Nos. 11772340, 11672315), the Youth Innovation Promotion Association of CAS (Grant No. 2015015).

Biography: Chang Xu (1992-), Female, Master

Corresponding author: Yi-wei Wang,

E-mail:wangyw@imech.ac.cn with commercial software, such as the CFX, the FLUENT $^{[20,21]}$ and other open source software, such as the OpenFOAM ${ }^{[22-24]}$.

The interaction between the free surface and the cavitating flow is a very complex and interesting problem. Based on the numerical and experimental methods mentioned above, the flow characteristics and the mechanism of unsteady cavities were studied. The mechanism of main control parameters, such as the submerged depth, the cavitation number, the Froude number, and the gravity, which affect the cavitating flow, were analyzed based on experiments and numerical simulations ${ }^{[1,9,25]}$. Wang ${ }^{[13,26]}$ studied the cloud cavitating flow around an axisymmetric projectile near the free surface, including the effect of the free surface on the cavity shape, the cavity evolution process, the re-entrant jet inside the cavity, and the vortex structure. The CFD simulations were conducted, and the results were found to be consistent with the water tank experiment data. Moreover, the atmospheric ventilation flow around a blunt body near the free surface was discussed ${ }^{[27]}$. Ventilated cavitation occurs when the model is sufficiently close to the free surface. The entrainment of a strong air into the ca- 


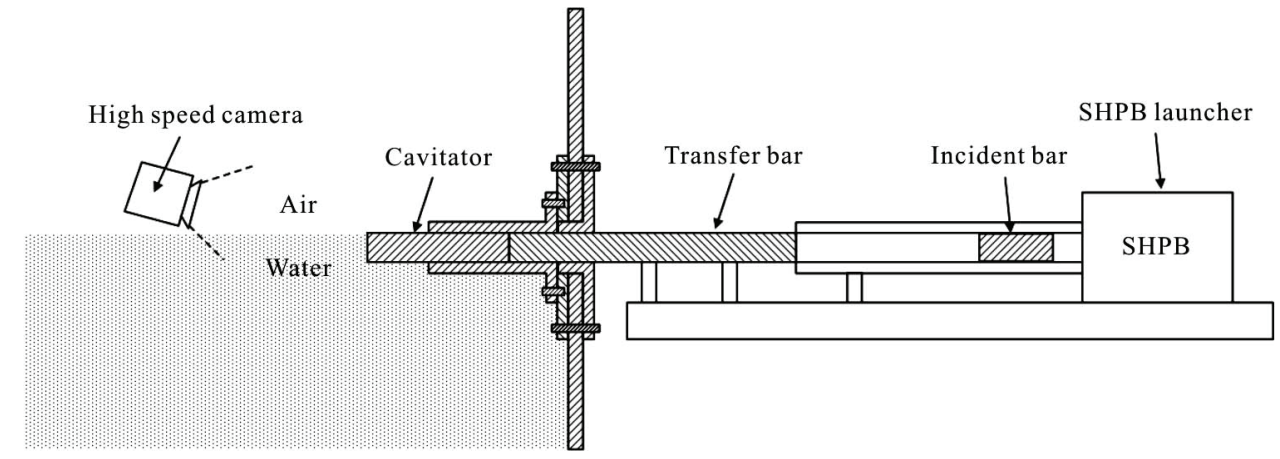

Fig.1 Water tank test facilities

vity on the upper side of the blunt body induces a large and stable cavity. The effects of other boundary conditions, such as that of the near-wall on the cloud cavitating flow around vehicles were also discussed in the recent studies ${ }^{[28-30]}$

In this work, the water tank experiments and the numerical simulations are performed to analyze the effect of the free surface on the cloud cavitating flow around a blunt body in various submerged depths. The accuracy of the numerical method and the mesh independence are verified. The cavity evolution processes, including the cavity growth, the re-entrant jet, the cavity shedding, and the collapse, can be observed through the experimental data. We first discuss the effects of the free surface on the cavity length, the thickness, and the cavity evolution period. Then, the effects of the free surface on the cavity stability, the asymmetry, and the thickness and the velocity of the re-entrant jet inside the cavity of various submerged depths are examined under a series of working conditions.

\section{Water tank experiment}

The water tank test facilities are shown in Fig.1. The tested model in the experiment is a slender, polished stainless-steel cylinder of $37 \mathrm{~mm}$ in diameter. The launching process is based on the SplitHopkinson pressure bar technology ${ }^{[6]}$, which could accelerate the launched model to a speed of $18.5 \mathrm{~m} / \mathrm{s}$ in less than $50 \mu \mathrm{s}$. The entire cavity evolution process could be recorded by a high-speed camera with 25000 frames per second. The water temperature is approximately $20^{\circ} \mathrm{C}$. In the following sections, the cavity evolution will be mainly discussed based on experimental pictures and numerical results. The cavity shape changes with the submerged depth at the launch time, the cavitation phenomenon can be classified by the shape development into the cloud cavitation ${ }^{[13]}$, the natural ventilation ${ }^{[27]}$ and the supercavitation as the submerged depth decreases. We mainly focus on the cloud cavitating flow in this paper with the submer- ged depth varying from $15 \mathrm{~mm}$ to $40 \mathrm{~mm}$. There will be no free surface effect on the cloud cavi- tating flow around the projectile when the distance between the upper side of the projectile and the free surface exceeds $40 \mathrm{~mm}$.

\section{Numerical methods}

\subsection{Governing equations}

The multiphase flow equations are extensively used for solving the water-liquid/water-vapor twophase flow problems. The governing and momentum equations are expressed as:

$$
\begin{aligned}
& \frac{\partial \rho}{\partial t}+\frac{\partial\left(\rho u_{j}\right)}{\partial x_{j}}=0 \\
& \frac{\partial\left(\rho u_{i}\right)}{\partial t}+\frac{\partial\left(\rho u_{i} u_{j}\right)}{\partial x_{j}}=-\frac{\partial p}{\partial x_{j}}+\frac{\partial}{\partial x_{j}}\left(\mu \frac{\partial u_{j}}{\partial x_{j}}\right)
\end{aligned}
$$

where $u_{i}$ is the velocity component in the $i$ direction, $\rho$ is the mixture density, $p$ is the pressure, and $\mu$ is the laminar viscosity, which can be defined as

$\mu=\left(1-\alpha_{v}\right) \mu_{l}+\alpha_{v} \mu_{v}$

where $\alpha$ is the volume fraction of the different phases, and $l$ and $v$ represent the liquid water and the water vapor, respectively. The mixture density $\rho$ is defined as

$\rho=\left(1-\alpha_{v}\right) \rho_{l}+\alpha_{v} \rho_{v}$

The transport equation of the water vapor volume fraction is

$$
\frac{\partial\left(\alpha_{v} \rho_{v}\right)}{\partial t}+\frac{\partial\left(\alpha_{v} \rho_{v} u_{j}\right)}{\partial x_{j}}=\dot{m}^{+}-\dot{m}^{-}
$$


Table 1 Numerical schemes and parameters

\begin{tabular}{cccccccccc}
\hline $\begin{array}{c}\text { Velocity } \\
\text { inlet }\end{array}$ & $\begin{array}{c}\text { Model } \\
\text { diameter }\end{array}$ & $\begin{array}{c}\text { Cavita- } \\
\text { tion } \\
\text { number }\end{array}$ & $\begin{array}{c}\text { Reynolds } \\
\text { number }\end{array}$ & $\begin{array}{c}\text { Froude } \\
\text { number }\end{array}$ & $\begin{array}{c}\text { Scheme in } \\
\text { time }\end{array}$ & $\begin{array}{c}\text { Pressure } \\
\text { interpola- } \\
\text { tion }\end{array}$ & $\begin{array}{c}\text { Scheme in } \\
\text { momentum }\end{array}$ & $\begin{array}{c}\text { Scheme in } \\
\text { volume } \\
\text { fraction }\end{array}$ & $\begin{array}{c}\text { Time } \\
\text { step size }\end{array}$ \\
\hline $18.5 \mathrm{~m} / \mathrm{s}$ & $37.0 \mathrm{~mm}$ & 0.579 & $7.61 \times 10^{5}$ & 30.7 & $\begin{array}{c}\text { Bounded } \\
\text { second- } \\
\text { order } \\
\text { implicit }\end{array}$ & $\begin{array}{c}\text { Body } \\
\text { force } \\
\text { weighted }\end{array}$ & $\begin{array}{c}\text { Bounded } \\
\text { central } \\
\text { differencing }\end{array}$ & $\begin{array}{c}\text { Modified } \\
\text { HRIC }\end{array}$ & $1 \times 10^{5} \mathrm{~s}$ \\
\hline
\end{tabular}

where $\dot{m}^{+}$and $\dot{m}^{-}$are the mass transfer rates of the evaporation and the condensation, respectively, which are derived from the Rayleigh-Plesset bubble dynamic equations as presented by Zwart et al. ${ }^{[31]}$.

$\dot{m}^{+}=F_{\text {vap }} \frac{3 a_{\text {nuc }}\left(1-\alpha_{v}\right) \rho_{v}}{R_{B}} \sqrt{\frac{2}{3} \frac{\max \left(p_{v}-p, 0\right)}{\rho_{l}}}$

$\dot{m}^{-}=F_{\text {cond }} \frac{3 \alpha_{v} \rho_{v}}{R_{B}} \sqrt{\frac{2}{3} \frac{\max \left(p-p_{v}, 0\right)}{\rho_{l}}}$

where $R_{B}=10^{-6} \mathrm{~m}$ is the generalized bubble radius, $p_{v}=2340 \mathrm{~Pa}$ is the saturated vapor pressure, $a_{\text {nuc }}=5 \times 10^{-4}$ is the nucleation site volume fraction, $F_{\text {vap }}=50$ is the evaporation coefficient, and $F_{\text {cond }}=$ 0.01 is the condensation coefficient. The selected parameter values are based on the work of Zwart et al.. The parameters are evaluated and found to work well for a variety of fluids and devices. The parameters and the recommended values of the cavitation model were extensively used ${ }^{[13]}$. In addition, several studies indicated that the parameters had a small effect on the results of the cloud cavitating flow within a certain range $^{[32]}$.

\subsection{Numerical schemes and parameters}

In this study, the commercial software FLUENT is used for simulating the cloud cavitating flow around a blunt body near the free surface. The $1.2 \mathrm{~m} \times 0.8 \mathrm{~m} \times$ $0.4 \mathrm{~m}$ computational domain and the defined boundary conditions include the velocity-inlet, the pressure-outlet, and no-slip wall, as shown in Fig.2, where half of the model is considered. The depth between the upper side of the blunt body and the free surface $(15 \mathrm{~mm})$ and the simulated velocity $(18.5 \mathrm{~m} / \mathrm{s})$ are the same as those in the water tank experiment. The tail effect on the cavity is neglected by using a semiinfinite projectile model. Other simulation conditions are consistent with the experimental conditions. During the calculation, the VOF method and the LES approach with the Smagorinsky-Lilly model are used for simulating the turbulent flow. Other detailed numerical schemes and parameters are shown in Table 1.

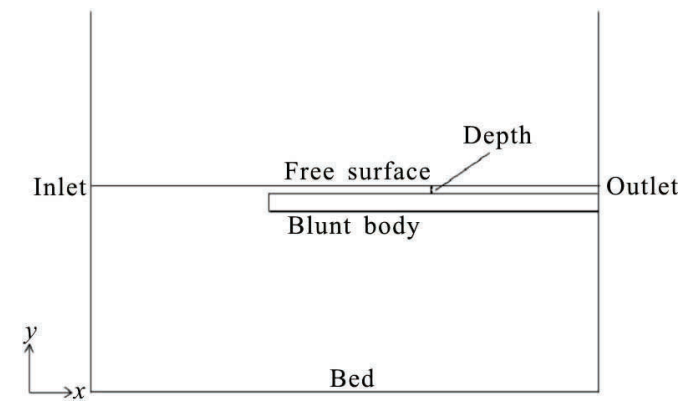

Fig.2 Computational domain and boundary conditions

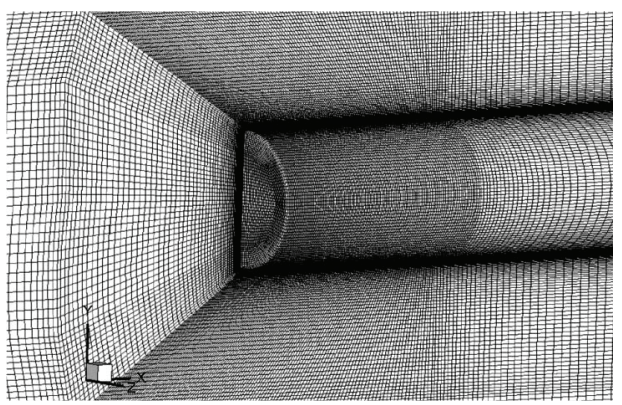

Fig.3 Mesh near the head of the projectile

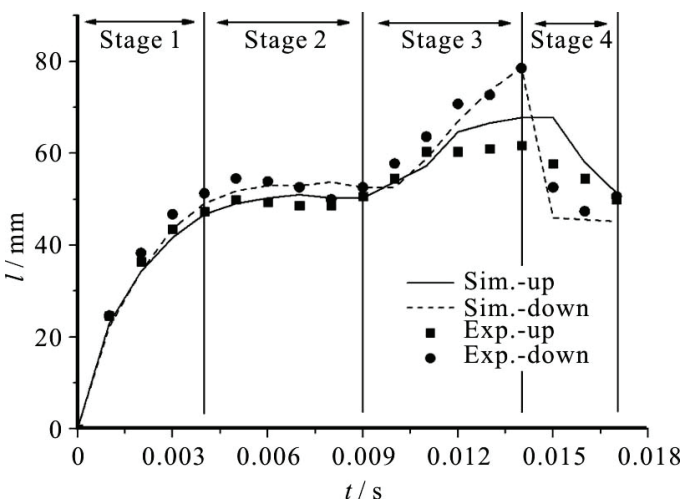

Fig.4 Comparison of cavity lengths on the upper and lower sides of the model between the experimental and simulated results

\subsection{Validation}

The numerical results of a block-structured mesh (Fig.3) with a cell number of approximately $4 \times 10^{6}$ are compared with the water tank experimental data in Fig.4. $l$ is the distance between the upper side of the 


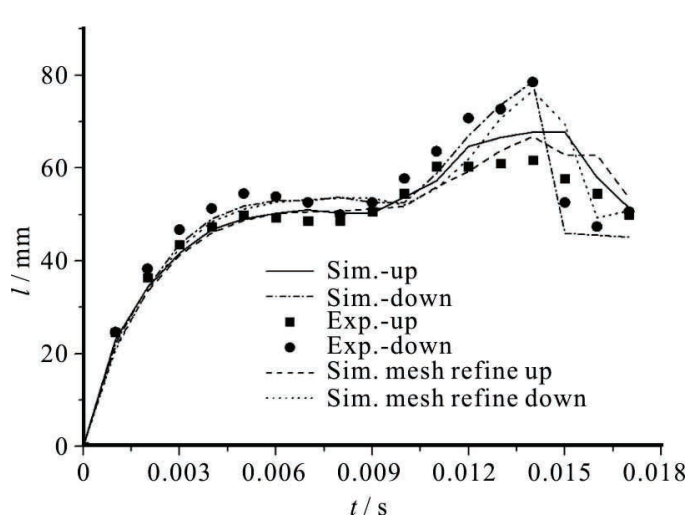

Fig.5 Comparison of simulated results of cavity length at the upper and lower sides of the model of original mesh and refined mesh, and experimental results

projectile and the free surface, $t$ is time. The first layer height is set at $1 \mathrm{~m}$ to ensure that $Y^{+}$is approximately equal to 1 . The total cell number is approximately $4 \times 10^{6}$ with a good orthogonality, which is refined around the model and near the free surface. The results are consistent with each other, which validates the accuracy of the numerical methods. The cavity evolution process shown in the figure includes four stages: the cavity growth, the re-entrant jet, the cavity shedding, and the collapse.

\subsection{Mesh independence study}

Based on the original mesh plan, a refined mesh is generated with a total cell number of $3 \times 10^{7}$. The mesh independence is confirmed by comparing the cavity length at the upper and lower sides of the blunt body among the experimental results, and the simulated results with the original mesh, and the refined mesh, as shown in Fig.5. The results of the new mesh plan are in good agreement with those of the previous models. The cavity shapes of the simulated results are also compared in Fig.6, which shows that the refined mesh simulation results are consistent with the original results of the cavity evolution. As the main features of the cavity evolution are our concern to a greater extent than other attributes, the mesh independence of the simulation method can be verified. The LES approach is widely used in the calculation of the cavitating flow nowadays, but without much validation and verification $(\mathrm{V} \& \mathrm{~V})$ study ${ }^{[33]}$. The $\mathrm{V} \& \mathrm{~V}$ is necessary for numerical calculations ${ }^{[34]}$ and the $V \& V$ research for the LES methods will be conducted in the future.

\section{Results and discussions}

Figure 7 shows the comparison of cavity patterns between the experiment and simulation results during the cavity evolution process. The preceding four stages mentioned above can be clearly observed through the figures. The cavity is generated in the first stage. The re-entrant jet appears inside the end of the cavity and moves toward the shoulder of the model when the cavity turns into a stable shape. In the third stage, the re-entrant jet removes the cavity by interfering with the outside flow. Thereafter, the cavity shedding occurs. In the last stage, the cavity collapses, and the cavity length is significantly decreased. The differences of the cavity shape between the upper and lower sides of the body reflect the effect of the free surface on the cavitating flow. With a small upper constraint and the effect of the free surface, the upper side of the cavity has a larger curvature than that of the lower side cavity. Cavities can be thick and short

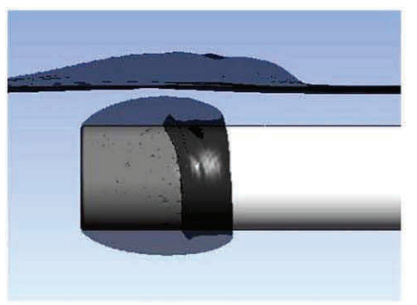

(a) $t=8 \mathrm{~ms}$

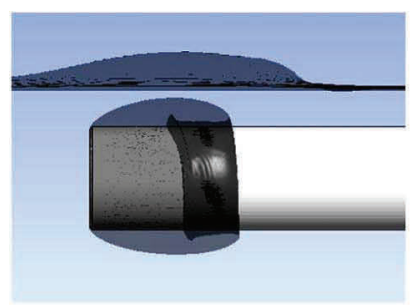

(b) $t=4 \mathrm{~ms}$

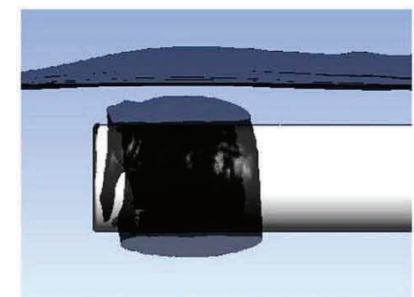

(a $\left.\mathrm{a}_{2}\right)=8 \mathrm{~ms}$

(a) Original mesh

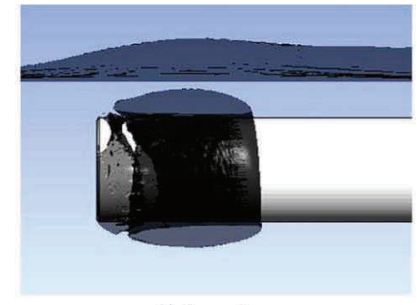

( $\left.\mathrm{b}_{2}\right) t=8 \mathrm{~ms}$

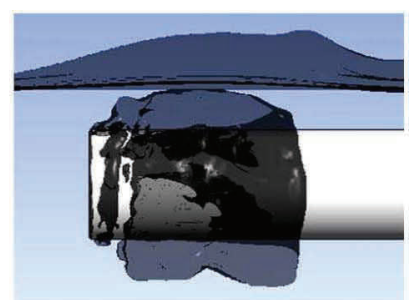

(a) $t=12 \mathrm{~ms}$

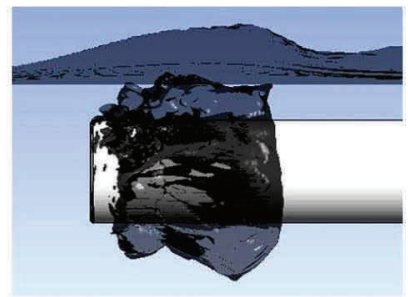

(b) $t=12 \mathrm{~ms}$

(b) Refined mesh

Fig.6 (Color online) Comparison of the cavity evolutions between simulated results with the original mesh and the refined mesh 


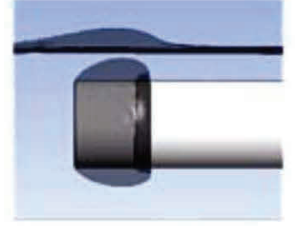

(a) $t=2 \mathrm{~ms}$

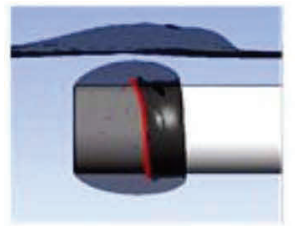

(a) $t=4 \mathrm{~ms}$

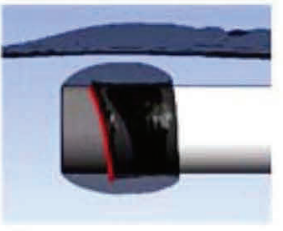

(a) $t=6 \mathrm{~ms}$

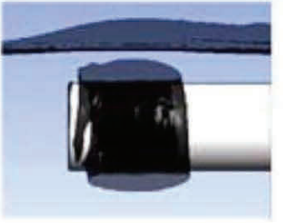

(a) $t=8 \mathrm{~ms}$

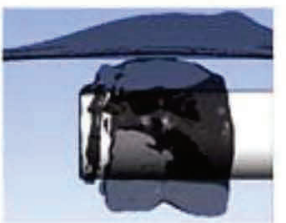

(a) $t=12 \mathrm{~ms}$

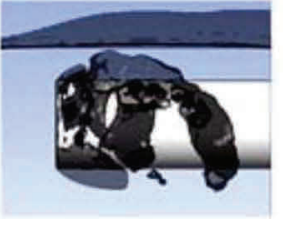

(a) $t=16 \mathrm{~ms}$

(a) Sim. results

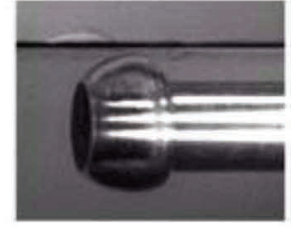

(b) $t=2 \mathrm{~ms}$

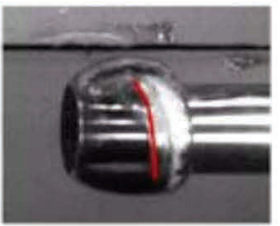

(b) $t=4 \mathrm{~ms}$

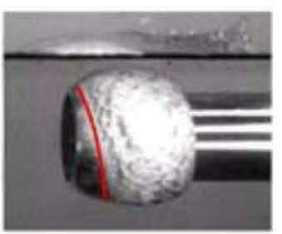

(b) $t=6 \mathrm{~ms}$

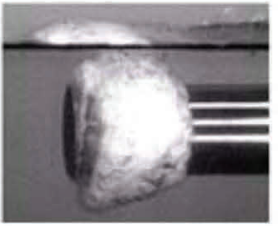

(b) $t=8 \mathrm{~ms}$

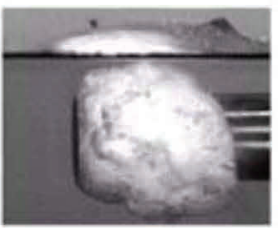

(b) $t=12 \mathrm{~ms}$

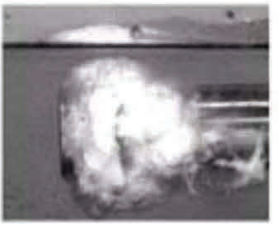

(b) $t=16 \mathrm{~ms}$

(b) Exp. results
Fig.7 (Color online) Comparison of cavity patterns between experiment and simulation results at $t=2 \mathrm{~ms}, 4 \mathrm{~ms}, 6 \mathrm{~ms}$, $8 \mathrm{~ms}, 10 \mathrm{~ms}, 12 \mathrm{~ms}$ and $16 \mathrm{~ms}$. Re-entrant jets are marked by red lines

near the free surface. The entire cavity evolution period is also shortened. Detailed discussions and analyses of the flow characteristics and the mechanism of the cavity are given in Ref.[13].

In this study, various submerged depths $(15 \mathrm{~mm}$, $20 \mathrm{~mm}, 25 \mathrm{~mm}, 30 \mathrm{~mm}$ and $40 \mathrm{~mm}$ ) are considered to analyze the cavity stability and the asymmetry, the re-entrant jet thickness, and the velocity with the free surface effect. If the submerged depth is reduced, a natural ventilation will occur ${ }^{[27]}$.

\subsection{The effect of free surface on cavity stability and asymmetry}

Plotted data are shown in Figures 8 and 9. The cavity stability on the upper side of the blunt body increases with the decrease of the submerged depth, whereas the stability on the lower side cavity is generally unchanged. The cavity asymmetry increases with the decrease of the submerged depth. The relationship between the average cavity length difference and the submerged depth can be expressed by the following equation

$\Delta l=-0.01 d^{2}+0.32 d+2.52$

where $l$ is the cavity length, and $d$ is the submerged depth.

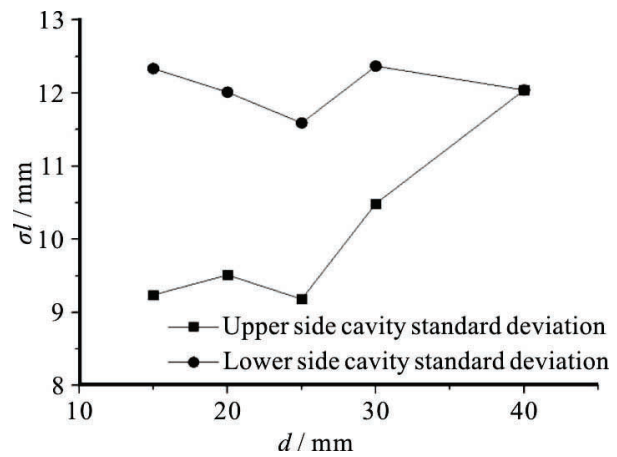

Fig.8 Standard deviation of cavity length $(\sigma l)$ on the upper and lower sides of blunt body at $1 \mathrm{~ms}-17 \mathrm{~ms}$

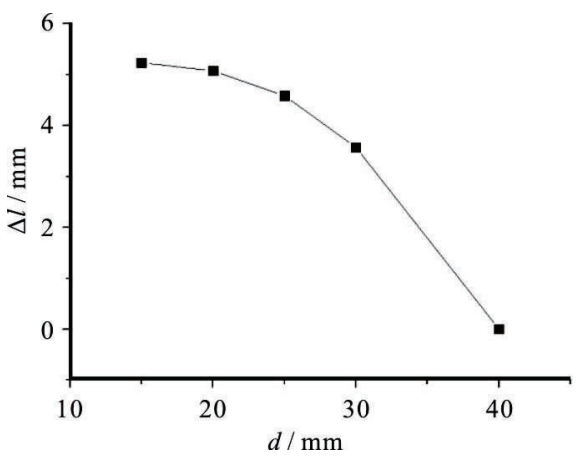

Fig.9 Average value of cavity lengths $(\Delta l)$ on the upper and lower sides of blunt body at $1 \mathrm{~ms}-17 \mathrm{~ms}$

\subsection{The effect of free surface on re-entrant jet} thickness and velocity

The re-entrant jet is one of the important factors for the cavity instability. By putting the velocity contour charts on the symmetry plane of the model, we can clearly see the re-entrant jet inside the cavity based on the numerical results. Figure 10 shows the velocity distribution around the blunt body and the cavi- 


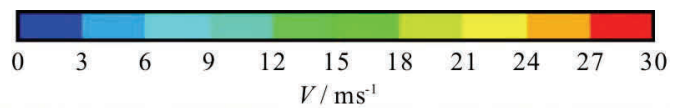

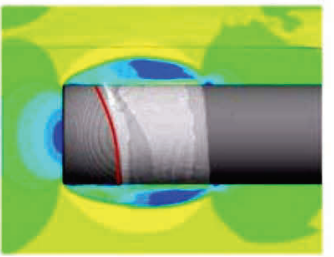

(a) $15 \mathrm{~mm}$

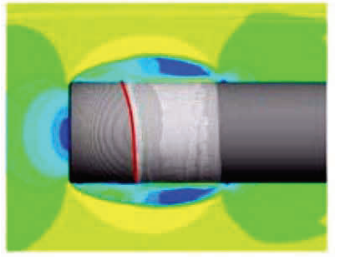

(c) $25 \mathrm{~mm}$

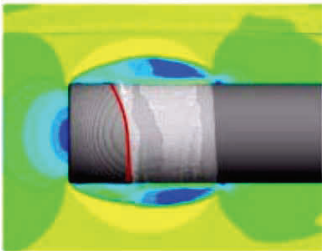

(b) $20 \mathrm{~mm}$

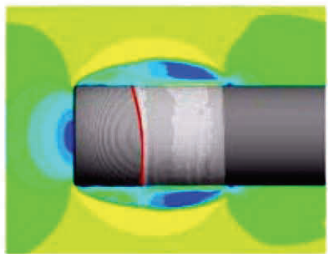

(d) $30 \mathrm{~mm}$

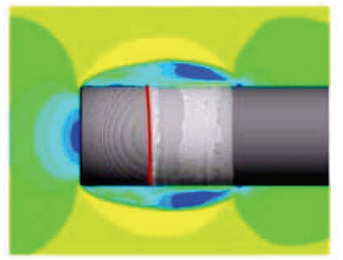

(e) $40 \mathrm{~mm}$

Fig.10 (Color online) Comparison of simulation results for various submerged depths $(15 \mathrm{~mm}, 20 \mathrm{~mm}, 25 \mathrm{~mm}, 30 \mathrm{~mm}$ and $40 \mathrm{~mm}$ ) at $6 \mathrm{~ms}$ (velocity contour charts show the velocity distribution around the model at the added symmetry plane)

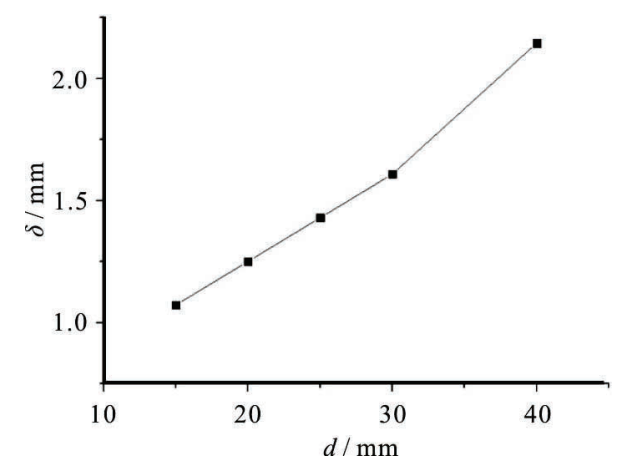

Fig.11 Thickness of re-entrant jet inside the cavity for various submerged depths $(15 \mathrm{~mm}, 20 \mathrm{~mm}, 25 \mathrm{~mm}, 30 \mathrm{~mm}$ and $40 \mathrm{~mm})$ at $6 \mathrm{~ms}$

tating flow on the model at $t=6 \mathrm{~ms}$. With the increase of the distance between the free surface and the model, the difference between the cavity length on the upper and lower sides of the body decreases. The thickness of the re-entrantjet inside the cavity at $t=6 \mathrm{~ms}$ is plotted in Fig.11, which shows that the thickness of the re-entrant jet is proportional to the water layer thickness. When the model is sufficiently close to the free surface, the re-entrant jet on the upper side is very thin and does not have a sufficient strength to remove the cavity. Thus, several fluctuations of the cavity shape are found on the upper side; however, no shedding occurs ${ }^{[27]}$. The thin re-entrant jet also induces a stable cavity when the blunt body moves close to the free surface. The relationship between the reentrant jet thickness and the submerged depth can be expressed by the following linear equation

$\delta=0.0425 d+0.4$

where $\delta$ is the re-entrant jet thickness.

The re-entrant jet inside the cavity moves toward the shoulder of the blunt body during the cavity evolution. The re-entrant jet profiles are marked by red lines in Fig.12. Finally, the main cavity is removed by interfering with the outside flow at $t=8 \mathrm{~ms}$. Figures 13 and 14 compare the re-entrant jet velocities $\left(V_{\text {re-entry jet }}\right)$ of the simulated cases with various submerged depths $(15 \mathrm{~mm}, 20 \mathrm{~mm}, 25 \mathrm{~mm}$, $30 \mathrm{~mm}$ and $40 \mathrm{~mm}$ ) in terms of the re-entrant jet length from the end of the main cavity to the re-entrant jet front inside the cavity. Generally, the re-entrant jet velocity increases as the submerged depth decreases. The re-entrant jet inside the upper side cavity of the blunt rapidly moves under the free surface effect. The re-entrant jet takes a considerable time to reach the leading edge of the hydrofoil due to the increase of the cavity length and the decrease of the speed of the re-entrant jet.

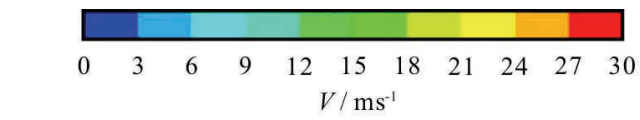

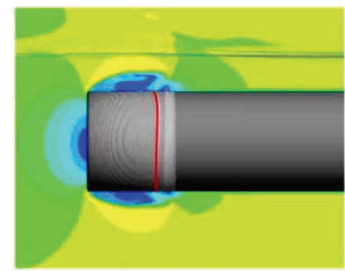

(a) $t=2 \mathrm{~ms}$

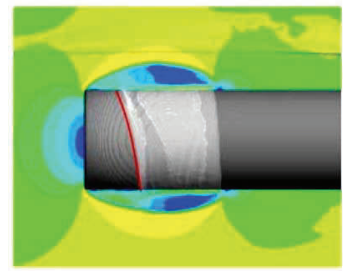

(c) $t=6 \mathrm{~ms}$

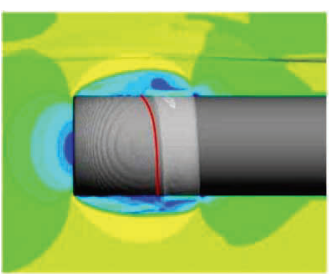

(b) $t=4 \mathrm{~ms}$

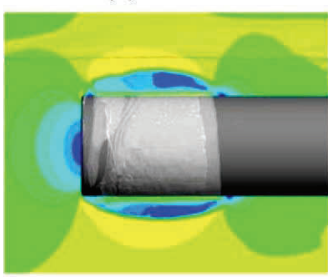

(d) $t=8 \mathrm{~ms}$
Fig.12 (Color online) Cavity evolution of simulation results with submerged depth of $15 \mathrm{~mm}$ at $2 \mathrm{~ms}, 4 \mathrm{~ms}, 6 \mathrm{~ms}$ and $8 \mathrm{~ms}$ (velocity contour charts show the velocity distribution around the model at the added symmetry plane) 


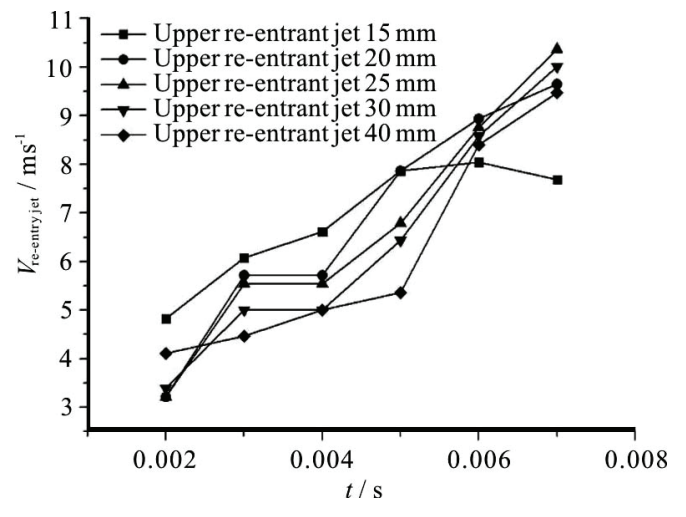

Fig.13 The re-entrant jet velocities of the simulated cases with various submerged depths $(15 \mathrm{~mm}, 20 \mathrm{~mm}, 25 \mathrm{~mm}$, $30 \mathrm{~mm}$ and $40 \mathrm{~mm}$ ) at $6 \mathrm{~ms}$

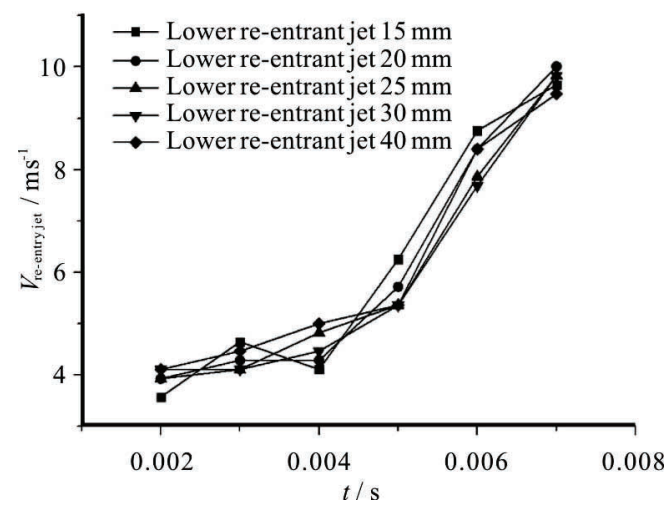

Fig.14 The re-entrant jet velocities of the simulated cases with various submerged depths $(15 \mathrm{~mm}, 20 \mathrm{~mm}, 25 \mathrm{~mm}$, $30 \mathrm{~mm}$ and $40 \mathrm{~mm}$ ) at $6 \mathrm{~ms}$

\section{Conclusions}

In this study, the effect of the free surface on the cloud cavitating flow around an underwater- launched blunt body is analyzed. The results of the water tank experiment and the CFD simulation are in good agreement. The mesh independence study is also carried out. The results of a series of water tank experiments and simulations for various submerged depths are analyzed.

Generally, the effect of the free surface on the cavitating flow around the blunt body is enhanced with the decrease of the submerged depth. The cavity on the upper side of the model is stable, thick, and short under the free surface effect. The cavity asymmetry, the difference between the upper and lower side cavities, increases as the submerged depth decreases.

The thickness of the re-entrant jet is proportional to the water layer thickness as shown by the simulation results. Therefore, the thin re-entrant jet also induces a stable cavity when the blunt body moves close to the free surface. In addition, the re-entrant jet velocity increases as the submerged depth decreases. The free surface effect near the blunt body can induce a fast re-entrant jet inside the upper side cavity.

The cavitating flow around the model near the free surface is complex. Apart from the submerged depth of the model, many other control parameters, such as the head type of the projectile and the boundary conditions, may influence the cavity. The author will focus on the effect of the free surface on the cavitating flow in case of wave movement in the future. Further study on the V\&V research with the LES methods is also necessary. In this study, the results are limited to typical working conditions for a typically shaped model, and an in-depth analysis is required.

\section{References}

[1] Franc J. P., Michel J. M. Fundamentals of cavitation [J]. Fluid Mechanics and Its Applications, 2005, 76(11): 1-46.

[2] Wang G., Senocak I., Wei S. et al. Dynamics of attached turbulent cavitating flows [J]. Progress in Aerospace Sciences, 2001, 37(6): 551-581.

[3] Knapp R. T., Daily J. W., Hammitt F. G. Cavitation [M]. New York, USA: McGraw-Hill, 1970.

[4] Brennen C. E. Cavitation and bubble dynamics [M]. Oxford, UK: Oxford University Press, 1995.

[5] Leroux J. B., Coutierdelgosha O., Astolfi J. A. A joint experimental and numerical study of mechanisms associated to instability of partial cavitation on two-dimensional hydrofoil [J]. Physics of Fluids, 2005, 17(5): 515-13.

[6] Wei Y. P., Wang Y. W., Fang X. et al. A scaled underwater launch system accomplished by stress wave propagation technique [J]. Chinese Physics Letters, 2011, 28(2): 024601-72.

[7] Hu C. L., Wang G. Y., Huang B. et al. The inception cavitating flows over an axisymmetric body with a blunt head-form [J]. Journal of Hydrodynamics, 2015, 27(3): 359-366.

[8] Faltinsen O. M. Hydrodynamics of high-speed marine vehicles $[\mathrm{M}]$. Cambridge, UK: Cambridge University Press, 2005.

[9] Faltinsen O. M., Semenov Y. A. The effect of gravity and cavitation on a hydrofoil near the free surface [J]. Journal of Fluid Mechanics, 2008, 597: 371-394.

[10] Bal S. High-speed submerged and surface piercing cavitating hydrofoils, including tandem case [J]. Ocean Engineering, 2007, 34(14): 1935-1946.

[11] Bal S. The effect of finite depth on 2D and 3D cavitating hydrofoils [J]. Journal of Marine Science and Technology, 2011, 16(2): 129-142.

[12] Bal S, Kinnas S. A. A BEM for the prediction of free surface effects on cavitating hydrofoils [J]. Computational Mechanics, 2002, 28(3-4): 260-274.

[13] Wang Y., Wu X., Huang C. et al. Unsteady characteristics of cloud cavitating flow near the free surface around an axisymmetric projectile [J]. International Journal of Multiphase Flow, 2016, 85: 48-56.

[14] Ji B., Long Y., Long X. P. et al. Large eddy simulation of turbulent attached cavitating flow with special emphasis 
on large scale structures of the hydrofoil wake and turbulence-cavita-tion interactions [J]. Journal of Hydrodynamics, 2017, 29(1): 27-39.

[15] Ji Bin, Luo X. W., Peng X. X. et al. Three-dimensional large eddy simulation and vorticity analysis of unsteady cavitating flow around a twisted hydrofoil [J]. Journal of Hydrodynamics, 2013, 25(4): 510-519.

[16] Xu C., Wang Y., Huang C. et al. Cloud cavitating flow that surrounds a vertical hydrofoil near the free surface $[\mathrm{J}]$. Journal of Fluids Engineering, 2017, 139(10): 101302.

[17] Ma J., Hsiao C. T., Chahine G. L. A physics based multiscale modeling of cavitating flows [J]. Computers and Fluids, 2017, 145: 68-84.

[18] Ma J., Oberai A. A., Drew D. A. et al. A quantitative subgrid air entrainment model for bubbly flows-plunging jets [J]. Computers and Fluids, 2010, 39(1): 77-86.

[19] Cheng H. Y., Long X. P., Ji B. et al. Numerical investigation of unsteady cavitating turbulent flows around twisted hydrofoil from the Lagrangian viewpoint [J]. Journal of Hydrodynamics, 2016, 28(4): 709-712.

[20] Kanfoudi H., Lamloumi H., Zgolli R. Numerical investigation for steady and unsteady cavitating flows, advances in modeling of fluid dynamics [M]. Rijeka, Croatia: INTECH Open Access Publisher, 2012.

[21] Wu Q., Huang B., Wang G. Numerical simulation of transient flows around a 3D pitching hydrofoil [J]. Advances in Mechanical Engineering, 2014, 7(2): 808034.

[22] Yu X. X., Huang C. G., Du T. Z. et al. Study of characteristics of cloud cavity around axisymmetric projectile by large eddy simulation [J]. Journal of Fluids Engineering, 2014, 136(5): 051303.

[23] Bensow R. E., Bark G. Implicit LES predictions of the cavitating flow on a propeller [J]. Journal of Fluids Engineering, 2010, 132(4): 041302.

[24] Pendar M. R., Roohi E. Investigation of cavitation around 3D hemispherical head-form body and conical cavitators using different turbulence and cavitation models [J]. Ocean Engineering, 2016, 112: 287-306.

[25] Dawson T. E. An experimental investigation of a fully cavitating two-dimensional flat plate hydrofoil near a free surface [J]. California Institute of Technology, 1959, 11(12): 1651-1655.
[26] Wang Y. W., Xu C., Huang J. et al. Study on flow characteristics and stability mechanism of unsteady cavitating flow near the free surface [C]. Proceedings of the 14th National congress on Hydrodynamics and the 28th National Conference on Hydrodynamics. Changchun, 2017, 94-104(in Chinese).

[27] Wang Y. W., Xu C., Wu X. C. et al. Ventilated cloud cavitating flow around a blunt body close to the free surface [J]. Physical Review Fluids, 2017, 2(8): 084303.

[28] Yu C., Wang Y. W., Huang C. G. et al. Experimental and numerical investigation on cloud cavitating flow around an axisymmetric projectile near the wall with emphasis on the analysis of local cavity shedding [J]. Ocean Engineering, 2017, 140: 377-387.

[29] Xu C., Wang Y. W., Huang C. G. et al. Analysis of Nearwall effect on cloud cavitating flow that surrounds an axisymmetric projectile using large eddy simulation with Cartesian cut-cell mesh method [J]. European Journal of Mechanics-B/Fluids, 2018, 67: 15-24.

[30] Xu C., Yu C., Huang J. et al. Experimental and numerical analysis of cloud cavitating flow that surrounds an axisymmetric projectile in shallow water [C]. Proceedings of the 14th National Congress on Hydrodynamics and the 28th National Conference on Hydrodynamics. Changchun, China, 2017, 518-524(in Chinese).

[31] Zwart P. J., Gerber A G., Belarmri T. A two-phase on model for predicting cavitation dynamics [C]. Fifth International Conference on Multi-phase Flow. Yokohama, Japan, 2004.

[32] Yu X., Wang Y., Huang C. et al. Study on the influence of phase change rate on cloud cavitation [J]. Procedia Engineering, 2013, 61(7): 204-206.

[33] Long Y., Long X. P., Ji B. et al. Verification and validation of URANS simulations of the turbulent cavitating flow around the hydrofoil [J]. Journal of Hydrodynamics, 2017, 29(4): 610-620.

[34] Xing T. A general framework for verification and validation of large eddy simulation [J]. Journal of Hydrodynamics, 2015, 27(2): 163-175. 